\title{
REVIEW OF COOLING SOLUTIONS FOR COMPACT ELECTRONIC DEVICES
}

\author{
Janis Galins, Aigars Laizans, Ainars Galins \\ Latvia University of Life Sciences and Technologies, Latvia \\ janis.galins@llu.lv
}

\begin{abstract}
Nowadays, with the rapid development of robotics and automation, there is a need for more powerful, more compact data processing equipment that also emits more heat. Various electronics cooling solutions are already in use, others are in development. Each cooling solution has its advantages and disadvantages. Active cooling usually dissipates heat more efficiently, but passive cooling is more reliable, especially when the electrical system is exposed to aggressive environmental influences. The possibility of using graphene in the manufacture of electrical equipment components is widely studied. Graphene could significantly improve the efficiency of passive cooling because its thermal conductivity is much better than copper.
\end{abstract}

Key words: cooling system; electronics cooling; thermal management; heat dissipation.

\section{Introduction}

The use of electronic devices in agricultural production facilities is increasing. The amount of data processed for automated equipment is increasing significantly and is expected to increase further in the near future. Increased data processing requires appropriate requirements to cooling of processor in compact enclosures. There are also other electronics components that emit significant amounts of heat. In order to avoid overheating of the electronic component, it is necessary to use appropriate heat dissipating systems. Most of electronic components must not exceed $120{ }^{\circ} \mathrm{C}$ operating temperatures. Various technical solutions are available for cooling electronic components. Usually air convection cooling is used. If the electronic circuit is covered with a compound, conductive cooling is provided. Cooling quality depends on thermal conductivity of the compound resin. This study discusses both traditional and innovative solutions and evaluates the application possibilities for achieving positive results. The aim of the work is to find an effective technology for cooling compact electronic devices.

Heat Transfer Fundamentals

The rate at which heat is conducted through a material is proportional to the area normal to the heat flow and to the temperature gradient along the heat flow path. For a one-dimensional, steady state, the rate of the heat flow is expressed by Fourier's equation:

$$
Q=k A \frac{\Delta T}{L},
$$

where $\mathrm{k}$ - thermal conductivity, $\mathrm{W}(\mathrm{m} \mathrm{K})^{-1 ;}$

$\mathrm{Q}$ - rate of heat flow, W;

A - contact area, $\mathrm{m}^{2}$;

$\mathrm{L}$ - distance of heat flow, $\mathrm{m}$;

$\Delta T$ - temperature difference, $\mathrm{K}$.

Thermal conductivity of a material can be defined as the rate of heat transfer through a unit thickness of the material per unit area and per unit temperature difference. The thermal conductivity of a material is a measure of the ability of the material to conduct heat. A high value for thermal conductivity indicates that the material is a good heat conductor, and a low value indicates that the material is a poor heat conductor or insulator. The thermal conductivities of some common materials at room temperature are given in Table 1.

Table 1

\section{The thermal conductivities of some materials at} room temperature (Cengel, 2008)

\begin{tabular}{|c|c|}
\hline Material & Thermal conductivity $\mathrm{k}, \mathrm{W}(\mathrm{m} \mathrm{K})^{-1}$ \\
\hline Diamond & 2300 \\
\hline Silver & 429 \\
\hline Copper & 401 \\
\hline Gold & 317 \\
\hline Aluminium & 237 \\
\hline Iron & 80.2 \\
\hline Mercury & 8.54 \\
\hline Water & 0.613 \\
\hline Air & 0.026 \\
\hline
\end{tabular}

Pure crystals and metals have the highest thermal conductivities, and gases and insulating materials the lowest. Liquid metals such as mercury and sodium have high thermal conductivities and are very suitable for use in applications where a high heat transfer rate to a liquid is desired. The lattice component of thermal conductivity strongly depends on the way the molecules are arranged. For example, diamond, which is a highly ordered crystalline solid, has the highest known thermal conductivity $2300 \mathrm{~W}(\mathrm{~m} \mathrm{~K})^{-1}$ at room temperature. Composite materials made of diamond and copper with the thermal conductivity of $768 \mathrm{~W}$ $(\mathrm{m} \mathrm{K})^{-1}$ can be prepared by pressureless infiltration (Jia et al., 2019; Parashchuk, 2016). Despite their higher price, diamond/copper heat sinks are used in the cooling of sensitive electronic components such 
as power diode lasers because of the excellent thermal conductivity of diamond.

Another inherent thermal property of a material is its thermal resistance $\mathrm{R}\left[\mathrm{K} \mathrm{W}^{-1}\right]$, as defined in Equation 2.

$$
R=\frac{\Delta T}{Q}
$$

Thermal resistance is a material property to resist a heat flow when there is a temperature difference between two faces of the material (Cengel, 2008; Digestibility \& Diets, 2007; Welty et al., 2007). It may be associated with the conduction of heat. The thermal resistance concept is widely used in practice because it is intuitively easy to understand and it has proven to be a powerful tool in the solution of a wide range of heat transfer problems.

Although the process of convection is very complex, the rate of convection heat transfer is observed to be proportional to the temperature difference and is conveniently expressed by Newton's law of cooling as:

$$
\dot{q}_{c o n v}=h\left(T_{s}-T_{f}\right)
$$

or

$$
\dot{Q}_{c o n v}=h A_{s}\left(T_{s}-T_{f}\right),
$$

where $\dot{q}_{\text {conv }}$ - convective heat flux, $\mathrm{W} \mathrm{m}^{-2}$;

$\mathrm{h}$ - heat transfer coefficient, $\mathrm{W}\left(\mathrm{m}^{2} \mathrm{~K}\right)^{-1}$;

$T_{S}$ - temperature of the solid surface, $\mathrm{K}$;

$T_{f}$ - temperature of the surrounding fluid, $\mathrm{K}$;

$\dot{Q}_{\text {conv }}$ - heat transfer rate, W;

$A_{s}$ - contact area of heat transfer surface, $\mathrm{m}^{2}$ (Cengel, 2008; Welty et al., 2007).

Convection heat transfer coefficient $\mathrm{h}$ depends on the conditions in the boundary layer, which are influenced by the surface geometry, the nature of the fluid motion, and an assortment of fluid thermodynamic and transport properties as shown in Table 2.
Convection with fluid phase change can provide more effective heat transfer coefficient values than forced convection in liquids or gases.

\section{Cooling solutions for compact electronic devices}

Smartphones, tablets, and other similar mobile devices are becoming more multifunctional and capable of handling higher data traffic in less time. The more compact the device becomes, the more difficult it is to create a suitable cooling system so that it does not overheat. The cost of the thermal management hardware must be small compared to the overall system cost (Fujitsu Laboratories Ltd, 2015; Pelonis, 2014). Different cooling technologies are being researched to find suitable for compact electrical equipment.

\section{Passive air cooling}

Most of today's compact electrical appliances use passive air cooling. Passive cooling uses natural convection and heat dissipation by utilizing a heat spreader or a heat sink to maximize the radiation and convection heat transfer modes (SimScale, 2019). Convection type heat transfer is often combined with conduction. Heatsinks are used for heating components, which help to dissipate heat in the ambient air. Often, the hot component is placed in a sealed housing where the air circulation flow rate is very low, so the machine can overheat for a longer period of time (Ahmadi et al., 2015; Mehrtash \& Tari, 2013; Sidik et al., 2017). Passive air cooling can be used to cool low-heat parts. For more efficient heat dissipation, thermal bridges or heat pipes of copper, aluminum or other material with good thermal conductivity may be used. Copper and aluminum not only conduct heat well, but also electricity, so the thermal bridges can be supplemented with silicone pads that provide electrical insulation. If the heat has to be transferred from a solid body to another solid body, then the thermal interface materials must be used for direct contact to fill the air gaps. The main advantages of passive cooling are energy efficiency and low cost.

Active air cooling

The heating components are usually equipped with heatsinks that increase the area of the heat transfer surface.

\section{Typical values of the convection heat transfer coefficient}

(Cengel, 2008; Niezgoda-Zelasko \& Zelasko, 2014)

\begin{tabular}{|c|c|c|}
\hline \multicolumn{2}{|c|}{ Process } & Heat transfer coefficient $\mathrm{h}, \mathrm{W}\left(\mathrm{m}^{2} \mathrm{~K}^{-1}\right.$ \\
\hline \multirow{2}{*}{ Free convection } & Gases & $2-25$ \\
\cline { 2 - 3 } & Liquids & $50-1000$ \\
\hline \multirow{2}{*}{ Forced convection } & Gases & $25-250$ \\
\cline { 2 - 3 } & Liquids & $100-20000$ \\
\hline Convection with phase change & Boiling or condensation & $2500-100000$ \\
\hline
\end{tabular}


Solid materials and fluid compatibility (LYTRON, 2019)

\begin{tabular}{|c|c|c|c|c|}
\hline \multirow{2}{*}{ Solid material } & \multicolumn{4}{|c|}{ Heat transfer fluid } \\
\cline { 2 - 5 } & Tap water & Glycols & Deionized Water & $\begin{array}{c}\text { Dielectric Fluids } \\
\text { (Fluorinert, PAO) }\end{array}$ \\
\hline Copper & $\mathrm{x}$ & $\mathrm{x}$ & $\mathrm{x}$ \\
\hline Aluminium & & $\mathrm{x}$ & $\mathrm{x}$ \\
\hline Stainless Steel & $\mathrm{x}$ & $\mathrm{x}$ & $\mathrm{x}$ & $\mathrm{x}$ \\
\hline
\end{tabular}

The fan creates a turbulent airflow that cools the heatsink and removes heat. Different types of fans can be integrated into electronics, such as computer cases, or are attached to CPUs, hard drives or chipsets, to maintain thermal conditions and reduce failure risk (SimScale, 2019). Over time, dust is sucked into the cooling system inlet ducts and pollutes the interior of the unit, covers the components, and decreases cooling efficiency. There are cases of dust clogging the fan causing overheating of the electrical equipment (Angelini et al., 2017; Park, Lee, 2017; Shi et al., 2017). This type of cooling is not applicable to closed systems that need to be operated under aggressive environmental conditions - wet, dusty and corrosive gases. Different filters are used to purify the intake air, but they reduce cooling efficiency. Filters should also be cleaned regularly. Cyclone technology for dust removal from the air can be used instead of filters (Galins et al., 2018). The fan generates noise. A higher flow velocity results in a better heat transfer, but larger noise (Gui et al., 2017). To reduce noise, feedback link can be used to control the fan speed depending on the required cooling intensity. Active cooling spends extra electricity, resulting in higher costs compared to passive cooling. Air cooling is limited by specific heat. To dissipate large amounts of power, a large mass flow rate is needed.

\section{Passive cooling with liquid heat transfer fluid}

Heat from the hot components is dissipated in the environment by convection. This technology is already used for cooling high power transformers. The transformer windings are located in a dielectric fluid that provides both insulation and winding cooling. Mineral oil, silicone fluid, synthetic or natural esters can be used as a dielectric fluid (CIGRE, 2010; Nadolny \& Dombek, 2017; Njombog Tanteh et al., 2014). Experimental studies indicate that the cooling capacity of the alternative liquid worsens with aging due to the exponential decrease of the viscosity with temperature (Ortiz et al., 2018). Heat transfer efficiency is greatly influenced by the thermal conductivity, specific thermal conductivity, viscosity and expansion coefficient of the heat carrier. As the liquid heats up, the viscosity decreases, thereby increasing the fluid flow rate and cooling efficiency. Convection can be combined with conduction. For example, the heat from the processor is transferred to the heatsink (conduction), but further away from the heatsink to the liquid heat transfer fluid (convection). For more efficient conduction heat transfer, thermal bridges with high thermal conductivity can be used. Active cooling with liquid heat transfer fluid

The heat transfer fluid such as water, oil, tosol or ester is supplied to the hot component using a circulation pump. The heating component is fitted with a collector or heat transfer tube through which the heat transfer fluid flows and transfers heat to the radiator or heat exchanger where it is dissipated or further transferred. The system is used with highpower heating components when a large amount of heat is released in one place, for example, cooling a $\mathrm{CO}_{2}$ laser lamp or copper mirrors etc. This technology is also suitable for the cooling of semiconductor processors, rectifiers and transistors (Hidalgo, 2016). Liquid cooling is able to achieve better heat transfer at much lower mass flow rates than air cooling. A lower flow velocity results in a lower noise. Water is one of the best heat transfer fluids due to its specific heat. Antifreeze is added to water to lower the freezing point of the water-based liquid and increase its boiling point. Ethanol serves to depress the freezing point of water below zero $-32{ }^{\circ} \mathrm{C}$ (Mohapatra, 2006). For a product to be reliable, heat transfer requires the selection of compatible solid materials and heat transfer fluid to avoid corrosion as shown in Table 3.

Heat pipes are usually made of copper or aluminium. Most cooling systems are compatible with water or glycol/water solutions but require special plumbing for compatibility with deionized water or a dielectric fluid such as polyalphaolefin (PAO). Nanofluids are another type of fluids considered as a working fluid of forced liquid heat transfer. The nanofluids may contain small solid particles of diamond, graphene, copper, $\mathrm{Al}_{2} \mathrm{O}_{3}, \mathrm{SiO}_{2}$ etc. (Kiseev \& Sazhin, 2019; Languri et al., 2018; Wang et al., 2019). Research confirms that adding particles improve thermal conductivity.

Thermoelectric cooling

Thermoelectric cooling technology (TEC) uses semiconductor-based electronic component - Peltier module that functions as a small heat pump. Heat flows through semiconductor from one face to another. The electric current simultaneously cools one face and heats 
the opposite face. A simple thermoelectric cooling system consists of two ceramic plates of p-type and n-type semiconductor materials between the plates. TEC can be used for precise temperature control of compact electrical equipment if refrigerants are not desirable. Improvement of thermoelectric cooling has been studied in many articles (Cai et al., 2019; Enescu \& Virjoghe, 2014; Lu et al., 2018; Sajid et al., 2017; Wang et al., 2017; Yang et al., 2017; Zhao \& Tan, 2014), but there are still various drawbacks to this technology. The use of Peltier elements is limited by the low energy efficiency of this element. The warm side heats up more than the cool side is cooled and the extra energy is required for the Peltier element to function. In order to cool down the Pelter element's hot side, active cooling is required, which complicates the use of technology.

\section{Phase Change Materials (PCMs)}

Phase Change Materials are materials whose phase change, from solid to liquid, and liquid to solid, are used to store and release heat. During melting, the material absorbs large amounts of heat from the environment. When the temperature drops, the material solidifies and releases heat (Advanced Cooling Technologies, 2019; Global E Systems, n.d.). Liquid-gas phase changes are impractical for thermal storage because large volumes or high pressures are required to store the materials in their gas phase. If the technology was previously used only for large electrical appliances such as a refrigerator, then today, this solution can take up very little space (Fok et al., 2010; Ganatra et al., 2018; Kaito et al., 2015; Setoh et al., 2010; Xie et al., 2019). Fujitsu has developed a loop heat pipe less than $1 \mathrm{~mm}$ thick that can be added to small, thin electronics. The heat pipe is a heat-transfer device that consists of an evaporator that absorbs heat from the heat source and a condenser that dissipates that heat away. Heat transfer fluid is encapsulated inside this closed loop as a coolant (Fujitsu Laboratories Ltd, 2015). The thin loop heat pipe can be installed on a heat-generating component, such as a central processing unit $\mathrm{CPU}$ or graphics processing unit GPU. Thicker PCM copper sheets are more effective for the thermal design. The technology used by Fujitsu works without a compressor and a pump. It does not increase the overall energy consumption of the device in order to diffuse heat.

\section{Thermal interface materials}

Thermal interface materials are used between two solid components to enhance the heat transfer efficiency. With increasing demands for better heat transfer, more efficient thermal interface materials are being developed. Thermal grease (also called thermal paste or heat sink compound) is used to eliminate air gaps from the interface area in order to maximize heat transfer. Grease 'dry-out' occurs due to the separation of the filler from the polymer matrix at elevated temperatures. This results in increased thermal resistance of the material (Gowda, 2007). The most effective (and most expensive) pastes consist almost entirely of liquid metal, usually a variation of the alloy galinstan, and have thermal conductivities in excess of $13 \mathrm{~W} \mathrm{(m} \mathrm{K})^{-1}$ (Meng et al., 2018; Roy et al., 2015; Zhang et al., 2019). These are difficult to apply evenly and have the greatest risk of causing malfunction due to spillage. These pastes contain gallium, which is highly corrosive to aluminium and cannot be used on aluminium heat sinks.

Thermal pads can be used for less heat generating components when electric insulation is important.

Future technologies for cooling compact electrical appliances

Graphene is a one-atom-thick layer of carbon atoms arranged in a hexagonal lattice. It is the thinnest compound known at one atom thick, strong with good thermal and electrical conductivity at room temperature. Researchers all over the world continue to constantly investigate and patent graphene to learn its various properties and possible applications, which include: transistors; computer chips; antennas, supercapacitors etc. (Su \& Zhang, 2018; Yue et al., 2019). Single layer graphene has a thermal conductivity above $2000 \mathrm{~W}\left(\mathrm{~m} \mathrm{~K}^{-1}\right.$ (Balandin, 2011). Thermal management of compact electronics could greatly benefit from graphene's ability to dissipate heat and optimize electronic function. Graphene's heat conductivity can be used in many ways, including thermal interface materials, thermal greases, heat spreaders, graphene-based nanocomposites etc.

\section{Results and Discussion}

The review of the methods, techniques, and technical solutions for the cooling of electronic circuit components has led to some noteworthy knowledge that will help effectively proceed with this important issue of the safety of electronic components. As a result of the research, the latest technologies of cooling of electronic components have been identified, which will significantly increase the cooling efficiency by removing heat directly from the heating surfaces. The heat transfer types discussed in the article are summarized in Figure 1 and Figure 2.

Today, the most innovative cooling system is with the conductive heat transfer, using graphene technology. This technique is still in the research phase and is starting to come into practice. The widespread use of these technologies will be expected in the next decade, as is the case with supermagnets and super capacitors today.

One of the most advanced is a conductive heat transfer solution using a heat collector with a passive heat pump based on a change in the physical state of 


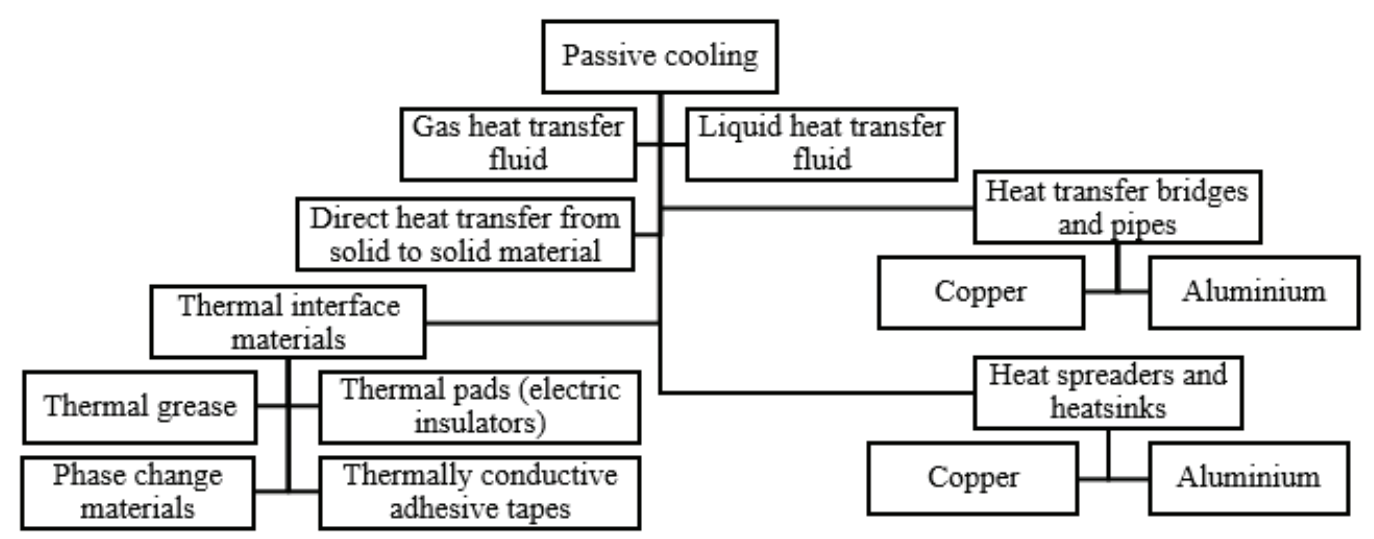

Figure 1. Types of passive cooling.

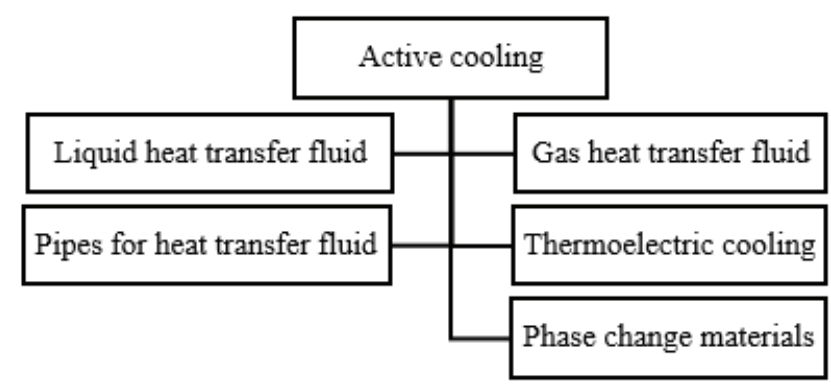

Figure 2. Types of active cooling.

the substance, a technology that has been used for a long time and successfully in renewable energy, in tube-type vacuum solar collectors.

Technically the simplest are passive convective cooling solutions, if the spreading heat capacity is small - some watts; thus no special solutions are needed. With expandable heat output, the heatsink dimensions - the area of the active surface and the mass - increases significantly, and there is a need to think about more efficient cooling techniques. The most common is convective active cooling with a fan. This cooling technique is not convenient, because there are moving mechanical parts and noise. There are also wear parts that collect and accumulate dust and pollute the electronics board. If dust filters are polluted, electronic elements can overheat.

The most reliable type of cooling is direct heat transfer. The electronic element is attached directly to the cooler or to the metal casing of the appliance using heat conducting grease or a thermal pad. Such technical solutions are widely used for electronic circuits in automotive, aviation and military industries.

Considering the previously mentioned, it will be necessary to select the most economically and technically suitable cooling technique for electronic components for each task. It may not be the most innovative, but one that provides the necessary results.

\section{Conclusions}

1. An overview of the cooling technology of electronic components confirms that several new and advanced technologies are currently available in parallel with the well-known technologies, which use heat pumps based on the change of the physical state of the heat transfer fluid, nanofluid technologies for heat transfer, and can provide efficient cooling at the compact technical performance.

2. At the moment, the latest heat transfer technology is based on the use of nano-carbon technologies, using graphene as a thermal transfer bridge. The graphene's thermal conductivity (above $2000 \mathrm{~W}$ $\left.(\mathrm{m} \mathrm{K})^{-1}\right)$ is considerably higher than that of copper $\left(401 \mathrm{~W}(\mathrm{~m} \mathrm{~K})^{-1}\right)$. This technology is expected to be widely used in the near future.

3. The choice of the cooling system for electronic components should be based primarily on technical and economic considerations, guaranteeing the safety of electronics, so the use of traditional cooling technologies will not decrease, but the introduction of advanced technologies will be determined by market demand and customer solvency. 


\section{References}

1. Advanced Cooling Technologies. (2019). Phase Change Material (PCM) Selection. Retrieved February 27, 2019, from https://www.1-act.com/products/pcm-heat-sinks/pcmselection/.

2. Ahmadi, M., Pakdaman, M.F., \& Bahrami, M. (2015). Pushing the limits of vertical naturally-cooled heatsinks; Calculations and design methodology. International Journal of Heat and Mass Transfer, 87, pp. 11-23. DOI: 10.1016/j.ijheatmasstransfer.2015.03.086.

3. Angelini, G., Bonanni, T., Corsini, A., Delibra, G., Tieghi, L., \& Volponi, D. (2017). Optimization of an axial fan for air cooled condensers. Energy Procedia, 126, pp. 754-761. DOI: 10.1016/j.egypro.2017.08.236.

4. Balandin, A.A. (2011). Thermal properties of graphene and nanostructured carbon materials. Nature Materials, 10(8), pp. 569-581. DOI: 10.1038/nmat3064.

5. Cai, Y., Wang, Y., Liu, D., \& Zhao, F.Y. (2019). Thermoelectric cooling technology applied in the field of electronic devices: Updated review on the parametric investigations and model developments. Applied Thermal Engineering, 148(November 2018), pp. 238-255. DOI: 10.1016/j.applthermaleng.2018.11.014.

6. Cengel, Y.A. (2008). Heat Transfer: A Practical Approach $2^{\text {nd }}$ Edition. PM World Journal. Retrieved February 27, 2019, from http://web.a.ebscohost.com/bsi/detail/detail?vid=4\&sid=255d93e3-d360-45caa768-9a8bd96ae785\%40sessionmgr4007\&hid=4209\&bdata=JnNpdGU9YnNpLWxpdmU\%3D\#AN=111 $093111 \& \mathrm{db}=\mathrm{bth}$.

7. CIGRE. (2010). Experiences in Service with New Insulating Liquids. Retrieved February 27, 2019, from http://static.mimaterials.com/midel/documents/sales/New_Experiences_in_Service_with_New_ Insulating_Liquids.pdf.

8. Incropera, F., Dewitt, D., Bergman, T., \& Lavine, A. (2007). Fundamentals of Heat and Mass Transfer Sixth Edition. DOI: 10.1109/TKDE.2004.30.

9. Enescu, D., \& Virjoghe, E.O. (2014). A review on thermoelectric cooling parameters and performance. Renewable and Sustainable Energy Reviews, 38, pp. 903-916. DOI: 10.1016/j.rser.2014.07.045.

10. Fok, S.C., Shen, W., \& Tan, F.L. (2010). Cooling of portable hand-held electronic devices using phase change materials in finned heat sinks. International Journal of Thermal Sciences, 49(1), pp. 109-117. DOI: 10.1016/j.ijthermalsci.2009.06.011.

11. Fujitsu Laboratories Ltd. (2015). Thin cooling device for compact electronics. Retrieved February 27 , 2019, from https://phys.org/news/2015-03-thin-cooling-device-compact-electronics.html.

12. Galins, J., Laizans, A., \& Galins, A. (2018). Increasing cyclone efficiency by using a separator plate. 24th Annual International Scientific Conference Research for Rural Development, 2018, 1, pp. 207-210. DOI: 10.22616/rrd.24.2018.032.

13. Ganatra, Y., Ruiz, J., Howarter, J.A., \& Marconnet, A. (2018). Experimental investigation of Phase Change Materials for thermal management of handheld devices. International Journal of Thermal Sciences, 129(April 2017), pp. 358-364. DOI: 10.1016/j.ijthermalsci.2018.03.012.

14. Global E Systems. (n.d.). GAIA Phase Change Materials. Retrieved February 27, 2019, from https://www. global-e-systems.com/en/phase-change-materials/what-are-phase-change-materials/

15. Gowda, A. (2007). Reliability Testing Of Thermal Greases. Retrieved March 10, 2019, from https://www. electronics-cooling.com/2007/11/reliability-testing-of-thermal-greases/.

16. Gui, L., Chen, L., Wang, C., Chen, J., Li, Y., \& He, Y. (2017). Aerodynamic noise prediction of a centrifugal fan considering the volute effect using IBEM. Applied Acoustics, 132(July 2016), pp. 182-190. DOI: 10.1016/j.apacoust.2017.10.015.

17. Hidalgo, P. (2016). How to Design a Liquid Cooled System. Retrieved March 7, 2019, from https://semitherm.org/wp-content/uploads/2017/04/How-to-design-liquid-cooled-system.pdf.

18. Jia, J., Bai, S., Xiong, D., Wang, J., \& Chang, J. (2019). Effect of tungsten based coating characteristics on microstructure and thermal conductivity of diamond/ $\mathrm{Cu}$ composites prepared by pressueless infiltration. Ceramics International, (November 2018), pp. 1-9. DOI: 10.1016/j.ceramint.2019.02.156.

19. Kaito, Y., Tomizawa, Y., Takeda, R., Kuroda, A., \& Sasaki, K. (2015). Experimental and numerical study on phase change material (PCM) for thermal management of mobile devices. Applied Thermal Engineering, 98, pp. 320-329. DOI: 10.1016/j.applthermaleng.2015.12.056.

20. Kiseev, V., \& Sazhin, O. (2019). Heat transfer enhancement in a loop thermosyphon using nanoparticles/ water nanofluid. International Journal of Heat and Mass Transfer, 132, pp. 557-564. DOI: 10.1016/j. ijheatmasstransfer.2018.11.109.

21. Languri, E.M., Davidson, J., Nawaz, K., Johnson, W., Mashali, F., Kerns, D., \& Cunningham, G. (2018). Thermo-physical properties of diamond nanofluids: A review. International Journal of Heat and Mass Transfer, 129, pp. 1123-1135. DOI: 10.1016/j.ijheatmasstransfer.2018.10.033. 
22. Lu, X., Zhao, D., Ma, T., Wang, Q., Fan, J., \& Yang, R. (2018). Thermal resistance matching for thermoelectric cooling systems. Energy Conversion and Management, 169(May), pp. 186-193. DOI: 10.1016/j.enconman.2018.05.052.

23. LYTRON. (2019). The Best Heat Transfer Fluids for Liquid Cooling. Retrieved March 8, 2019, from https://www.lytron.com/Tools-and-Technical-Reference/Application-Notes/The-Best-Heat-TransferFluids-for-Liquid-Cooling.

24. Mehrtash, M., \& Tari, I. (2013). A correlation for natural convection heat transfer from inclined plate-finned heat sinks. Applied Thermal Engineering, 51(1-2), pp. 1067-1075. DOI: 10.1016/j. applthermaleng.2012.10.043.

25. Meng, Y., Li, S., Jia, W., Tao, D., Tian, Y., \& Bai, P. (2018). Tribological properties of liquid-metal galinstan as novel additive in lithium grease. Tribology International, 128(July), pp. 181-189. DOI: 10.1016/j. triboint.2018.07.036.

26. Mohapatra, S.C. (2006). An Overview of Liquid Coolants for Electronics Cooling. Retrieved March 8, 2019, from https://www.electronics-cooling.com/2006/05/an-overview-of-liquid-coolants-for-electronicscooling/.

27. Nadolny, Z., \& Dombek, G. (2017). Thermal properties of mixtures of mineral oil and natural ester in terms of their application in the transformer. E3S Web of Conferences, 19, p. 01040. DOI: 10.1051/ e3sconf/20171901040.

28. Niezgoda-Zelasko, B., \& Zelasko, J. (2014). Free and forced convection on the outer surface of vertical longitudinally finned tubes. Experimental Thermal and Fluid Science, 57, pp. 145-156. DOI: 10.1016/j. expthermflusci.2014.04.014.

29. Njombog Tanteh, D., Yousef Al Liddawi, S., Ssekasiko, D., \& Eriksson, M. (2014). Properties of transformer oil that affect efficiency.

30. Ortiz, A., Delgado, F., Ortiz, F., Fernández, I., \& Santisteban, A. (2018). The aging impact on the cooling capacity of a natural ester used in power transformers. Applied Thermal Engineering, 144(July), pp. 797803. DOI: 10.1016/j.applthermaleng.2018.08.049.

31. Parashchuk, V.V. (2016). On Efficiency of Power Diode Lasers Using Diamond Heat Sinks. Materials Today: Proceedings, 3, pp. S165-S170. DOI: 10.1016/j.matpr.2016.02.028.

32. Park, M.J., \& Lee, D.J. (2017). Sources of broadband noise of an automotive cooling fan. Applied Acoustics, 118, pp. 66-75. DOI: 10.1016/j.apacoust.2016.10.007.

33. Pelonis, S. (2014). How to Cool Small Electronic Devices. Retrieved February 27, 2019, from https:// www.pelonistechnologies.com/blog/three-challenges-in-cooling-compact-electronic-devices.

34. Roy, C.K., Bhavnani, S., Hamilton, M.C., Johnson, R.W., Nguyen, J.L., Knight, R.W., Harris, D.K. (2015). Investigation into the application of low melting temperature alloys as wet thermal interface materials. International Journal of Heat and Mass Transfer, 85, pp. 996-1002. DOI: 10.1016/j. ijheatmasstransfer.2015.02.029.

35. Sajid, M., Hassan, I., \& Rahman, A. (2017). An overview of cooling of thermoelectric devices. Renewable and Sustainable Energy Reviews, 78(May), pp. 15-22. DOI: 10.1016/j.rser.2017.04.098.

36. Setoh, G., Tan, F.L., \& Fok, S.C. (2010). Experimental studies on the use of a phase change material for cooling mobile phones. International Communications in Heat and Mass Transfer, 37(9), pp. 1403-1410. DOI: 10.1016/j.icheatmasstransfer.2010.07.013.

37. Shi, H., Lu, Y., Huang, R., Yu, X., Lu, G., Liu, Z., ... Roskilly, A.P. (2017). Experiment study of multifans cooling module using different shroud structures for advanced vehicle thermal management system. Energy Procedia, 142, pp. 3968-3974. DOI: 10.1016/j.egypro.2017.12.305.

38. Sidik, N.A.C., Muhamad, M.N.A.W., Japar, W.M.A.A., \& Rasid, Z.A. (2017). An overview of passive techniques for heat transfer augmentation in microchannel heat sink. International Communications in Heat and Mass Transfer, 88(September), pp. 74-83. DOI: 10.1016/j.icheatmasstransfer.2017.08.009.

39. SimScale. (2019). Passive Cooling vs Active Cooling. Retrieved March 7, 2019, from https://www. simscale.com/blog/2017/01/active-and-passive-cooling/.

40. Su, R., \& Zhang, X. (2018). Size effect of thermal conductivity in monolayer graphene. Applied Thermal Engineering, 144(August), pp. 488-494. DOI: 10.1016/j.applthermaleng.2018.08.062.

41. Wang, X., Wang, Y., Yang, X., \& Cao, Y. (2019). Numerical simulation on the LSPR-effective coreshell copper/graphene nanofluids. Solar Energy, 181(December 2018), pp. 439-451. DOI: 10.1016/j. solener.2019.02.018. 
42. Wang, Y., Shi, Y., \& Liu, D. (2017). Performance analysis and experimental study on thermoelectric cooling system coupling with heat pipe. Procedia Engineering, 205, pp. 871-878. DOI: 10.1016/j. proeng.2017.10.048.

43. Welty, J.R., Wicks, C.E., Wilson, R.E., \& Rorrer, G.L. (2007). Fundamentals of Momentum, Heat and Mass Transfer, $5^{\text {th }}$ Edition.

44. Xie, J., Lee, H.M., \& Xiang, J. (2019). Numerical study of thermally optimized metal structures in a Phase Change Material (PCM) enclosure. Applied Thermal Engineering, 148(August 2018), pp. 825-837. DOI: 10.1016/j.applthermaleng.2018.11.111.

45. Yang, J.-J., Cai, Y., Zhao, F.-Y., Liu, D., \& Wang, Y. (2017). Optimization of Thermoelectric Cooling System for Application in CPU Cooler. Energy Procedia, 105, pp. 1644-1650. DOI: 10.1016/j.egypro.2017.03.535.

46. Yue, Y., Meng, C., Li, M., Gao, J., Liu, C., Bao, H., ... Xie, D. (2019). Temperature dependent thermal transport in graphene paper above room temperature. Applied Thermal Engineering, 150(January), pp. 1252-1259. DOI: 10.1016/j.applthermaleng.2019.01.098.

47. Zhang, X.-D., Yang, X.-H., Zhou, Y.-X., Rao, W., Gao, J.-Y., Ding, Y.-J., ... Liu, J. (2019). Experimental investigation of galinstan based minichannel cooling for high heat flux and large heat power thermal management. Energy Conversion and Management, 185(February), pp. 248-258. DOI: 10.1016/j. enconman.2019.02.010.

48. Zhao, D., \& Tan, G. (2014). A review of thermoelectric cooling: Materials, modeling and applications. Applied Thermal Engineering, 66(1-2), pp. 15-24. DOI: 10.1016/j.applthermaleng.2014.01.074. 